\title{
Synovial Osteochondromatosis of the Hip
}

Synovial osteochondromatosis is an uncommon, monoarticular disease affecting mainly large joints ${ }^{1}$. It is a benign condition characterized by synovial membrane proliferation and metaplasia. The synovial lining of a joint undergoes nodular proliferation, and fragments may break off from the synovial surface into the joint. Fragments that may grow, calcify, or ossify may be found free within the joint cavity, or they may be embedded within the proliferating synovium, which may extend into the surrounding soft tissues. Pain and swelling, clicking during joint rotation, deviation of the joint, and limitation of its motion are often seen in these cases. However, some patients with synovial chondromatosis are asymptomatic, as in our case.

A 24-year-old man came limping to the Rheumatology Clinic due to right hip pain. The pain began after a fall when the bus he was riding made a sudden stop. Examination disclosed local tenderness with moderate limitation in flexion and lateral rotation of the hip. Radiographs (Figure 1) and computed tomography scan (Figure 2) revealed numerous calcified foci surrounding the head and neck of the femur. A diagnosis of synovial osteochondromatosis was made; this diagnosis would have been postponed if he had not fallen in the bus.

Treatment of patients with synovial osteochondromatosis involves surgical excision of the proliferating synovium ${ }^{2}$. Since recurrence is frequent after surgery, total synovectomy has been suggested as the preferred treatment.

ELDAD BEN-CHETRIT, MD, Head, Department of Rheumatology; YAAKOV H. APPLBAUM, MD,

Radiologist, Hadassah-Hebrew University Medical Center, Ein Kerem, Jerusalem, 12000 Israel.

E-mail: eldad@hadassah.org.il

\section{REFERENCES}

1. Knoeller SM. Synovial osteochondromatosis of the hip joint. Etiology, diagnostic investigation and therapy. Acta Orthop Belg 2001;67:201-10.

2. Boyer T, Dorfmann H. Arthroscopy in primary synovial chondromatosis of the hip: description and outcome of treatment. J Bone Joint Surg Br 2008;90:314-8.

J Rheumatol 2010;37:668-9; doi:10.3899/jrheum.090762

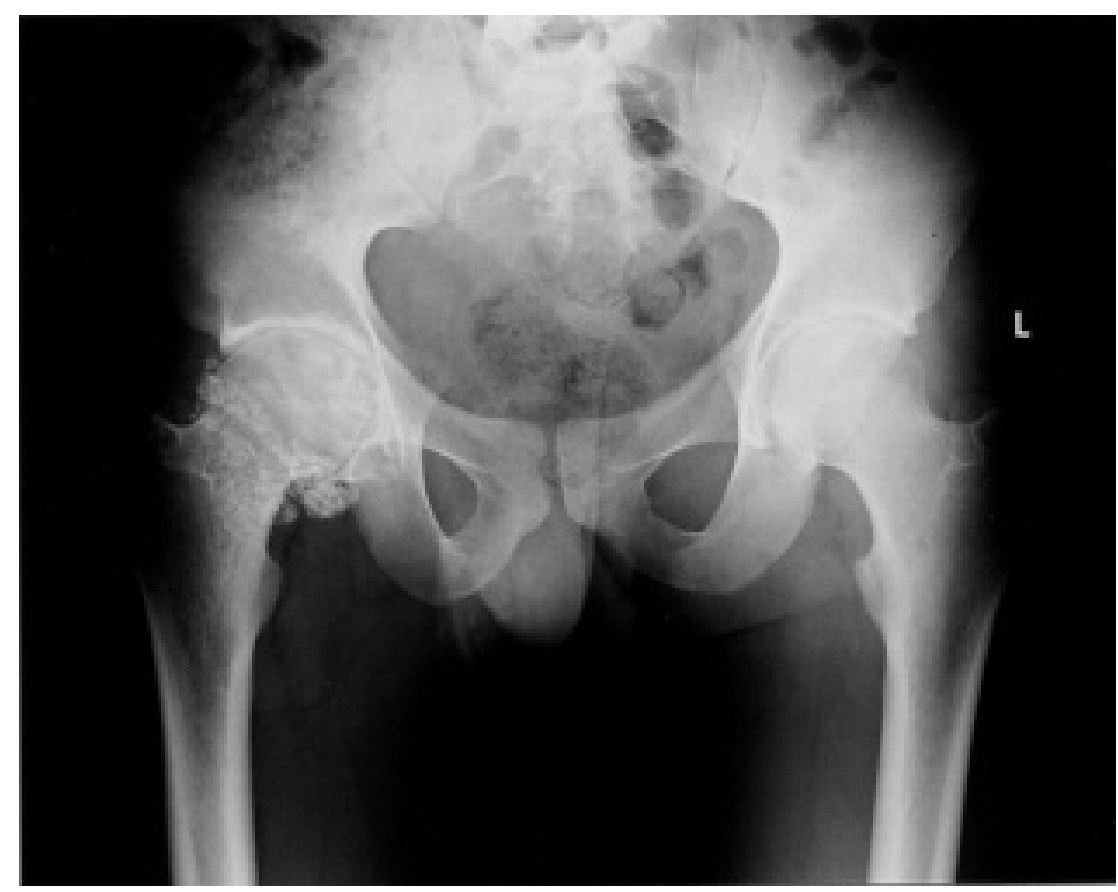

Figure 1. A radiograph reveals numerous calcified foci surrounding the head and neck of the femur. 


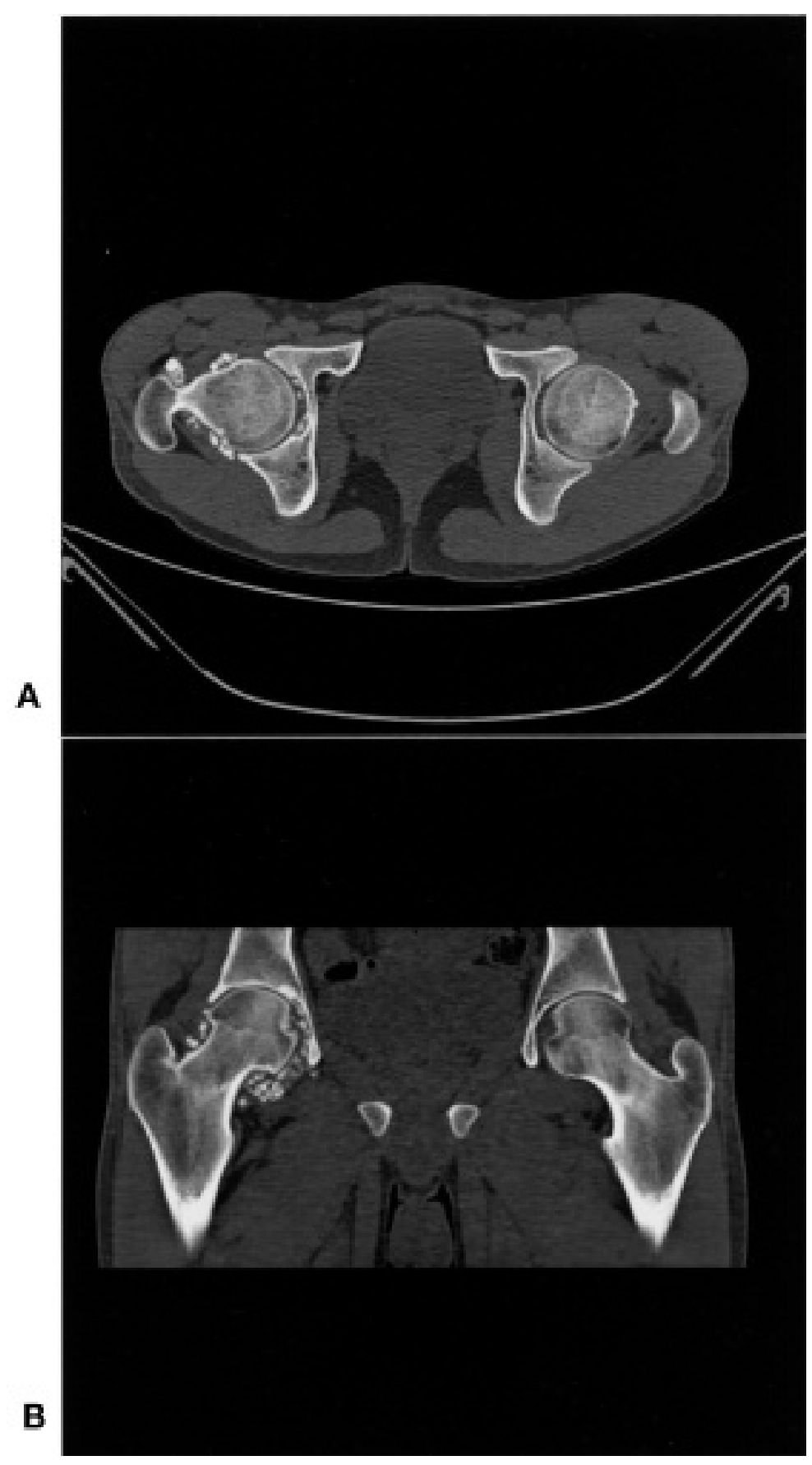

Figure 2. CT scan provides supporting evidence of calcified foci. 